\title{
Morphofunctional changes in urological syndrome in cats
}

\author{
Sergey Kartashov $^{1 *}$, Olga Bekker $^{1}$, Maria Oboeva ${ }^{1}$, and Evgenia Kartashova ${ }^{1}$ \\ ${ }^{1}$ Don State Technical University, 1 Gagarin Square, Rostov-on-Don, 344003, Russia
}

\begin{abstract}
Feline lower urinarytract disease (FLUTD) is a life-threatening condition in cats, especially in obstructive males. In a clinical situation, early diagnosis and correction of this condition is very important, otherwise the disease ends in death. FLUTD manifested by stranguria, pollakiuria, dysuria, and, in severe cases, hematuria and obstruction by anuria. This article discusses the features of the clinical course of FLUTD in 5 cats with obstructive idiopathic cystitis. Animals were selected with a similar history, they were animals from 3 to 7 years old, with exclusively home keeping, no walking and a diet consisting of dry commercial food. All animals underwent a complete clinical examination, complete blood count, general urinalysis, ultrasound of the genitourinary system and heart. For two weeks, the animals underwent a complex treatment consisting of infusion therapy, anesthesia with dexmedetomidine and NSAIDs (meloxicam), which led to clinical recovery in all animals within 14 days, all animals on an ongoing basis were prescribed amitriptyline, observation of the animals for 6 months did not reveal a relapse of the disease.
\end{abstract}

\section{Introduction}

Cats often suffer from a variety of medical conditions with a common clinical symptom, often referred to as lower urinary tract syndrome. This syndrome includes several symptoms, such as frequent (pollakiuria) and painful (stranguria) urination without polyuria, and hematuria (blood in the urine). Among diseases with this syndrome, idiopathic cystitis is in the first place, especially in young individuals; at an older age, this syndrome can appear in cats with urinary tract infection, urolithiasis and infiltrative processes in the lower urethral tract. Feline idiopathic cystitis usually appears at 2-6 years of age with a prevalence of $1.5-8 \%$ and very rarely before 1 or 10 years of age [4]. The condition may present with anorexia, fever, stranguria, dysuria, periuria and pollakiuria, and microscopic hematuria, but severe hematuria may occur in severe cases $[3,5]$. For this study, cats with idiopathic cystitis manifested by obstructive FLUTD were selected. In our study, all animals were constantly kept in the house and did not have the opportunity to walk, 4 cats were kept in rooms with one or more pets. All patients received combination feeding with commercial dry food, and only one cat received only wet food. Previous studies have shown that cats on a dry food diet were the most likely to suffer from

\footnotetext{
* Corresponding author: kartashovsn@gmail.com
} 
urological syndrome $[6,7]$. Since the disease is considered life-threatening, especially the obstructive form, it is very important to quickly resolve the obstruction, improve urodynamics and hemodynamics, and eliminate the consequences of obstruction. The article is devoted to clinical findings in that part of patients with obstructive FLUTD, in whom urodynamics recovered after analgesia.

The aim of the study was to find out whether anesthesia in cats with constructive FLUTD can completely resolve obstruction, clarify the main clinical symptoms, changes in blood tests, ophthalmic changes and characteristic sonographic aspects in this group of animals.

\section{Material and research method}

The data for the analysis were obtained from patients admitted to the clinical branches of DSTU for 6 months of 2018. A total of 22 patients with symptoms of feline urological syndrome were recruited. All cats previously treated in veterinary clinics for feline urological syndrome were excluded from the study, as well as animals with other comorbidities such as diabetes, hyperthyroidism, chronic kidney disease, and other systemic disorders. A history of life and illness was collected from all animals, as well as clinical signs of the disease and the degree of their manifestation. A total of 5 patients were selected with symptoms of obstructive urological syndrome in cats suffering from idiopathic cystitis. Patients were recruited no older than 6 years, without infection with MPT, with obstruction, which resolved on its own after anesthesia. Anesthesia was performed intravenously with dexmedetomidine at a dose of $5 \mu \mathrm{g} / \mathrm{kg}$ of animal weight, followed by infusion at a constant rate of $1 \mu \mathrm{g} / \mathrm{kg} / \mathrm{h}$ [2]. Hypovolemia and dehydration were eliminated in accordance with the AAHA/AAFP guidelines [1]. Clinical examination was carried out three times, at the time of admission of the animal, after the obstruction was removed and after the hypovolemia and dehydration were removed. Urine for analysis from all animals was taken by cystocentesis or during natural urination, if it was possible to quickly establish urination. Physicochemical analysis of urine included the determination of the physical characteristics of urine, the level of glucose, bilirubin, ketone bodies, hemoglobin content, $\mathrm{pH}$ using diagnostic U-strip strips, biochemical blood tests, determination of protein concentration and the ratio of protein to creatinine concentration were carried out on a biochemical analyzer A-15 BioSystems, urine density was determined using a refractometer.

All animals underwent a complete ophthalmologic examination, with fundus photography.

The animals underwent ultrasound examinations of the genitourinary tract and heart using a Mindray DC-7 ultrasound scanner.

\section{Results}

Of the 22 cats with FLUTD16, there was obstructive syndrome (72\%), while 7 of the cats with obstruction had fibrin and tripel phosphate urethral plugs (31\%). To eliminate the obstruction, repeated mechanical flushing of these formations from the urethra with saline solutions was required. In 5 of these animals and in 4 of the remaining animals, urinary tract infection was subsequently identified. The remaining five animals had no urethral plugs, no MMT infections, but had urethral obstruction and FLUTD symptoms (31\% of obstructed cats). We analgesized all of these animals with dexmedetomidine, within 5 to 15 minutes after the bolus was administered, the obstruction resolved in all these animals, and they began to urinate on their own. 
In animals, before analgesia, with signs of dehydration and pain syndrome, there was an increase in the frequency of respiratory movements to 41 , and the heart rate in a cat with signs of third degree hypovolemia and dehydration decreased to 108 beats / min, and the body temperature dropped below normal to $36.1^{\circ} \mathrm{C}$, which required warming this animal with heating pads. In animals with second-degree hypovolemia, there was a slight increase in RR (respiratory rate), HR (heart rate) was within normal limits. After infusion therapy was carried out in these animals and hypovolemia was eliminated, all animals showed a decrease in RR, in cats with a second degree of hypovolemia, there was a slight decrease in HR from $6,5 \%$ до $24,5 \%$, whereas in an animal with a third degree of hypovolemia this indicator increased by $24 \%$, in all cases after analgesia, elimination of hypovolemia and, if necessary, warming of animals, normalization of clinical parameters was noted (Table 1).

Table 1. Clinical symptoms in cats with obstructive FLUTD.

\begin{tabular}{|c|c|c|c|c|c|c|c|}
\hline \multirow{2}{*}{ Clinical data } & \multirow{2}{*}{ units } & \multicolumn{5}{|c|}{ animals } & \multirow[t]{2}{*}{ normal values } \\
\hline & & I & II & III & IV & $\mathrm{V}$ & \\
\hline \multicolumn{8}{|c|}{ clinical data at the time of admission } \\
\hline temperature & $\mathrm{C}^{0}$ & 37,2 & 38,4 & 37,7 & 36,9 & 36,1 & $38,0-38,9$ \\
\hline $\mathrm{RR}$ & $\mathrm{RR} / \mathrm{min}$ & 35 & 39 & 47 & 32 & 41 & $16-40$ \\
\hline HR & $\mathrm{HR} / \mathrm{min}$ & 165 & 163 & 172 & 188 & 108 & $120-220$ \\
\hline dehydration & $\%$ & 6 & 7 & 6 & 5 & 6 & no \\
\hline hypovolemia & $\%$ & 20 & 30 & 30 & 30 & 50 & no \\
\hline hematuria & score & 2 & 1 & 1 & 2 & 3 & no \\
\hline stranguria & score & 1 & 2 & 2 & 1 & 1 & no \\
\hline periuria & score & no & 1 & 2 & 1 & 2 & no \\
\hline obstruction & score & 2 & 3 & 3 & 3 & 2 & no \\
\hline \multicolumn{8}{|c|}{$\begin{array}{c}\text { clinical data after shock infusion, dexmedetomidine anesthesia and initiation of infusion } \\
\text { therapy, } 1 \text { day of therapy }\end{array}$} \\
\hline temperature & $\mathrm{C}^{0}$ & 39,1 & 38,9 & 38,5 & 38,4 & 39,2 & $38,0-38,9$ \\
\hline RR & $\mathrm{RR} / \mathrm{min}$ & 25 & 27 & 28 & 31 & 24 & $16-40$ \\
\hline HR & $\mathrm{HR} / \mathrm{min}$ & 155 & 141 & 135 & 151 & 142 & $120-220$ \\
\hline dehydration & $\%$ & - & no & 1 & 1 & no & no \\
\hline hematuria & score & 2 & no & no & 1 & 1 & no \\
\hline stranguria & score & no & 1 & 1 & no & no & no \\
\hline obstruction & score & no & no & no & no & no & no \\
\hline hematuria & score & 2 & 1 & 1 & 2 & 3 & no \\
\hline \multicolumn{8}{|c|}{ clinical data after elimination of dehydration 2-3 days of therapy } \\
\hline temperature & $\mathrm{C}^{0}$ & 38,2 & 38,5 & 38,3 & 38,7 & 39,1 & $38,0-38,9$ \\
\hline RR & $\mathrm{RR} / \mathrm{min}$ & 24 & 27 & 29 & 31 & 27 & $16-40$ \\
\hline HR & $\mathrm{HR} / \mathrm{min}$ & 123 & 132 & 129 & 133 & 122 & $120-220$ \\
\hline dehydration & $\%$ & - & - & - & - & - & - \\
\hline
\end{tabular}

The morphological parameters of blood were characterized by an increase in the number of erythrocytes in animals with dehydration of the 2-3rd degree of severity at the upper limit of the norm, and in two animals up to $11.2 ; 10.5 \times 1012 / 1$, respectively, while there was an increase in hemoglobin indices up to $151 \mathrm{~g} / 1$, and hematocrit up to $41 \%$ (Table 1.2). After elimination of hypovolemia and dehydration, red blood counts in all animals fell to the lower limit norm, and in one animal it is below the norm up to $4.8 \times 1012 / 1$, which indicates that in general, these animals have a relative erythrocytosis, which completely disappears after replenishing the fluid deficit in the body. The total number of leukocytes in FLUTD animals did not go beyond the parameters of healthy animals and ranged from 18.2 to $11.1 \times 109 / 1$; in our study, only one animal had neutrophilia with a shift of the nucleus to the left, while 4 out of 5 animals had unexpressed leukopenia, which was completely corrected during the next 3 days of therapy, pain relief and elimination of hypovolemia and 
dehydration (Table 2). In all animals, there were no changes in the number of eosinophils, basophils, and monocytes, the number of which varied within physiological limits both before and after the therapy. The platelet count in animals in our study also varied within the range of healthy animals before and after therapy.

Table 2. CBC scores in cats with obstructive FLUTD.

\begin{tabular}{|c|c|c|c|c|c|c|c|}
\hline $\begin{array}{c}\text { Complete } \\
\text { blood count } \\
\text { data }\end{array}$ & units & I & II & III & IV & V & normal values \\
\hline \multicolumn{7}{|c|}{ Complete blood count data at the time of admission } \\
\hline erythrocytes & $10^{12} / 1$ & 7,7 & 9,2 & 9,9 & 11,2 & 10,5 & $5,0-10,0$ \\
\hline hematocrit & $\%$ & 34 & 37 & 41 & 39 & 41 & $24-34$ \\
\hline hemoglobin & $\mathrm{g} / 1$ & 133 & 142 & 139 & 151 & 144 & $100-150$ \\
\hline leukocytes & $10^{9} / 1$ & 16,3 & 18,2 & 14,1 & 11,1 & 17,5 & $5,5-19,5$ \\
\hline platelets & $10^{9} / 1$ & 321 & 257 & 431 & 559 & 603 & $300-800$ \\
\hline neutrophils & $\%$ & 72 & 68 & 74 & 55 & 69 & $45-64$ \\
\hline lymphocytes & $\%$ & 25 & 29 & 22 & 41 & 30 & $27-36$ \\
\hline monocytes & $\%$ & 2 & 1 & 2 & 4 & 1 & $0-5$ \\
\hline eosinophils & $\%$ & 1 & 1 & 1 & - & - & $0-4$ \\
\hline basophils & $\%$ & - & 1 & 1 & - & - & $0-1$ \\
\hline \multicolumn{7}{|c|}{ Complete blood count data after elimination of dehydration $2-3$ days of therapy } \\
\hline erythrocytes & $10^{12} / 1$ & 5,7 & 5,3 & 6,1 & 4,8 & 5,5 & $5,0-10,0$ \\
\hline hematocrit & $\%$ & 27 & 28 & 30 & 27 & 29 & $24-34$ \\
\hline hemoglobin & $\mathrm{g} / 1$ & 129 & 112 & 115 & 101 & 108 & $100-150$ \\
\hline leukocytes & $10^{9} / 1$ & 11,2 & 9,9 & 11,2 & 7,5 & 12,3 & $5,5-19,5$ \\
\hline platelets & $10^{9} / 1$ & 551 & 375 & 421 & 459 & 647 & $300-800$ \\
\hline neutrophils & $\%$ & 55 & 58 & 55 & 61 & 60 & $45-64$ \\
\hline lymphocytes & $\%$ & 34 & 38 & 37 & 31 & 31 & $27-36$ \\
\hline monocytes & $\%$ & 6 & 2 & 5 & 6 & 4 & $0-5$ \\
\hline eosinophils & $\%$ & 5 & 2 & 3 & 2 & 4 & $0-4$ \\
\hline basophils & $\%$ & - & - & - & - & 1 & $0-1$ \\
\hline
\end{tabular}

Urinalysis revealed in all cats with FLUTD hematuria from latent to clinically expressed, urine density was within the normal range in 4 animals and only one showed a slight increase in this indicator, after infusion therapy in all animals, urine density decreased, and $\mathrm{pH}$ increased. (Table 3).

Table 3. OAM scores in cats with obstructive FLUTD.

\begin{tabular}{|c|c|c|c|c|c|c|}
\hline $\begin{array}{c}\text { Complete } \\
\text { blood count } \\
\text { data }\end{array}$ & I & II & III & IV & V & norm \\
\hline \multicolumn{7}{|c|}{ Complete blood count data at the time of admission } \\
\hline Density & 1.055 & 1.050 & 1.060 & 1.045 & 1.055 & $1.015-1.050$ \\
\hline $\mathrm{pH}$ & 6,8 & 6,71 & 6,9 & 6,2 & 6,3 & $5,5-7,0$ \\
\hline Erythrocytes & $3+$ & $2+$ & $3+$ & $2+$ & $1+$ & - \\
\hline \multicolumn{6}{|c|}{ Complete blood count data after elimination of dehydration $2-3$ days of therapy } \\
\hline Density & 1.020 & 1.025 & 1.020 & 1.035 & 1.025 & $1.015-1.050$ \\
\hline $\mathrm{pH}$ & 6,5 & 6,65 & 6,1 & 7,2 & 5,9 & $5,5-7,0$ \\
\hline Erythrocytes & - & - & - & - & - & - \\
\hline
\end{tabular}

An interesting tendency was noted during ultrasound examination of the heart; before infusion therapy, an increase in the thickness of the posterior wall of the left ventricle and interventricular septum in diastole was noted to values characteristic of feline hypertrophic cardiomyopathy, but after infusion therapy and elimination of hypovolemia, these 
indicators completely returned to normal. This is most likely due to an increase in the enddiastolic volume of the heart after an increase in the volume of circulating blood and venous return (Table 4). All animals showed no gross changes in the bladder wall.

Table 4. Ultrasound of the kidneys and heart in cats with obstructive FLUTD.

\begin{tabular}{|c|c|c|c|c|c|c|c|}
\hline \multirow{2}{*}{ Ultrasound data } & \multirow{2}{*}{ units } & \multicolumn{5}{|c|}{ animals } & \multirow[t]{2}{*}{ normal values } \\
\hline & & $\mathrm{I}$ & II & III & IV & $\mathrm{V}$ & \\
\hline \multicolumn{8}{|c|}{ Ultrasound data at the time of admission } \\
\hline $\begin{array}{l}\text { left ventricular posterior } \\
\text { wall thickness in systole }\end{array}$ & $\mathrm{mm}$ & 10 & 11 & 9 & 10,3 & 9,6 & $4,3-9,8$ \\
\hline $\begin{array}{l}\text { left ventricular posterior } \\
\text { wall thickness in diastole }\end{array}$ & $\mathrm{mm}$ & 6 & 5,8 & 5,6 & 6,1 & 5,5 & $4-5,5$ \\
\hline $\begin{array}{l}\text { the thickness of the } \\
\text { interventricular septum in } \\
\text { systole }\end{array}$ & $\mathrm{mm}$ & 9 & 8,9 & 8,7 & 10 & 9,3 & $4-9$ \\
\hline $\begin{array}{l}\text { the thickness of the } \\
\text { interventricular septum in } \\
\text { diastole }\end{array}$ & $\mathrm{mm}$ & 5,7 & 5,2 & 6,1 & 5,9 & 5,8 & $4-5,5$ \\
\hline $\begin{array}{c}\text { wall of the } \\
\text { interventricular septum }\end{array}$ & $\mathrm{mm}$ & 0,7 & 0,9 & 1,1 & 1 & 0,7 & $1,3-1,7$ \\
\hline pelvis & $\mathrm{mm}$ & 3 & 2 & 1 & 1 & 2 & - \\
\hline \multicolumn{8}{|c|}{$\begin{array}{c}\text { Ultrasound data after shock infusion, dexmedetomidine anesthesia and initiation of infusion } \\
\text { therapy, } 1 \text { day of therapy }\end{array}$} \\
\hline $\begin{array}{l}\text { left ventricular posterior } \\
\text { wall thickness in systole }\end{array}$ & $\mathrm{mm}$ & 7,3 & 7,6 & 7,7 & 5,9 & 8 & $4,3-9,8$ \\
\hline $\begin{array}{l}\text { left ventricular posterior } \\
\text { wall thickness in diastole }\end{array}$ & $\mathrm{mm}$ & 4,9 & 6 & 4,8 & 4,2 & 5,2 & $4-5,5$ \\
\hline $\begin{array}{l}\text { the thickness of the } \\
\text { interventricular septum in } \\
\text { systole }\end{array}$ & $\mathrm{mm}$ & 4,3 & 7 & 7,1 & 8 & 7,3 & $4-9$ \\
\hline $\begin{array}{l}\text { the thickness of the } \\
\text { interventricular septum in } \\
\text { diastole }\end{array}$ & $\mathrm{mm}$ & 5,3 & 5,1 & 4,7 & 5,1 & 4,3 & $4-5,5$ \\
\hline $\begin{array}{l}\text { wall of the } \\
\text { interventricular septum }\end{array}$ & $\mathrm{mm}$ & 1,4 & 1,8 & 1,2 & 1 & 1,5 & $1,3-1,7$ \\
\hline pelvis & $\mathrm{mm}$ & - & - & - & - & - & - \\
\hline \multicolumn{8}{|c|}{ Ultrasound data after elimination of dehydration 2-3 days of therapy } \\
\hline $\begin{array}{l}\text { left ventricular posterior } \\
\text { wall thickness in systole }\end{array}$ & $\mathrm{mm}$ & 7,3 & 7,7 & 7,8 & 6 & 8 & $4,3-9,8$ \\
\hline $\begin{array}{l}\text { left ventricular posterior } \\
\text { wall thickness in diastole }\end{array}$ & $\mathrm{mm}$ & 4,8 & 6 & 4,6 & 4 & 5,2 & $4-5,5$ \\
\hline $\begin{array}{l}\text { the thickness of the } \\
\text { interventricular septum in } \\
\text { systole }\end{array}$ & $\mathrm{mm}$ & 4,3 & 7 & 6,9 & 8 & 7,2 & $4-9$ \\
\hline $\begin{array}{l}\text { the thickness of the } \\
\text { interventricular septum in } \\
\text { diastole }\end{array}$ & $\mathrm{mm}$ & 5 & 5,3 & 4,9 & 5,2 & 4,3 & $4-5,5$ \\
\hline $\begin{array}{l}\text { wall of the } \\
\text { interventricular septum }\end{array}$ & $\mathrm{mm}$ & 1,5 & 1,6 & 1 & 1,2 & 1,4 & $1,3-1,7$ \\
\hline
\end{tabular}

In 5 cats, changes in the fundus were noted, characteristic of arterial hypertension. Changes were characterized from insignificant (Fig. 1) and moderate (Fig. 2), to pronounced tortuosity of vessels of the fundus and areas of hyperpigmentation (Fig. 1, 3). 


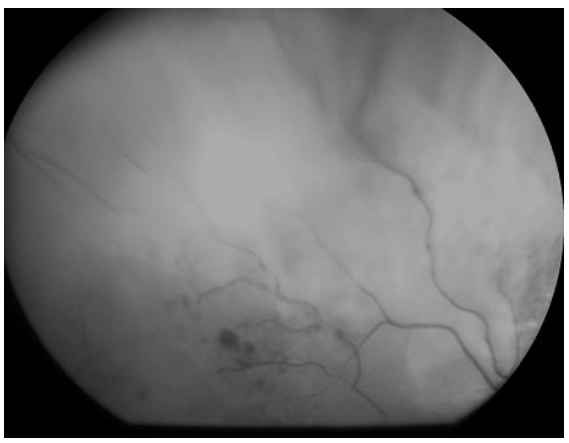

Fig. 1. There is a slight tortuosity of the vessels of the fundus.

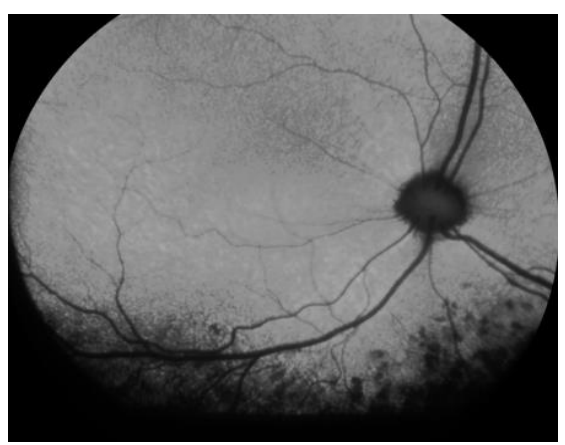

Fig. 2. Moderate tortuosity of the fundus vessels.

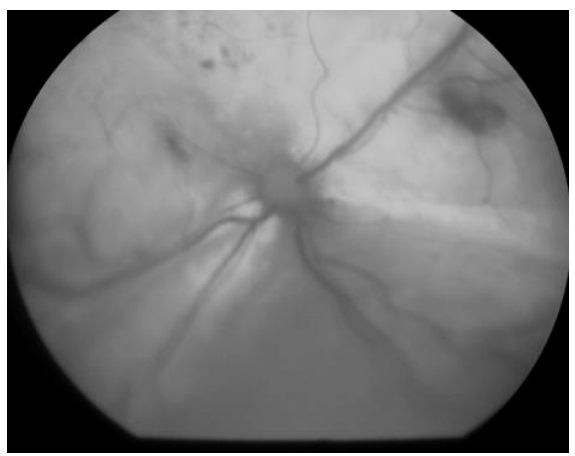

Fig. 3. Severe tortuosity of the fundus vessels.

It was difficult to say whether it was secondary to a disease of the lower urethral tract or it was a primary disease associated with changes in the activity of the sympathetic nervous system, which were the cause of idiopathic cystitis. Two of these animals had increased intraocular pressure.

\section{Discussion}

In our opinion, cats with obstructive FLUTD, which can be eliminated only with anesthesia, at least from a clinical point of view, it makes sense to separate them into a separate group, since they do not need to undergo bladder catheterization or treatment of urinary tract infections. These cats do not have gross changes in blood counts and changes in the genitourinary tract. These animals recover well from a critical state after anesthesia 
and elimination of dehydration and hypovolemia. As a rule, this can be done within the first two days of inpatient treatment $[1,2]$. Since in these animals we could not find any other problems besides the obstruction of the urethra, the spastic nature of this condition is more likely, we tend to diagnose these animals with idiopathic cystitis of cats, and later they were treated using elements of environmental modification and amitriptyline according to the well-known scheme [2 ].

\section{Output}

The most common risk factors for feline urological syndrome and idiopathic cystitis are overweight, low physical activity, and confinement that are too small for the animal [1]. In our study, $64 \%$ of the patients were cats that were constantly kept in the house and did not have the opportunity to walk, and $30 \%$ of the sick cats were animals kept in rooms with one or more pets. $34 \%$ of cats were fed a combination of commercial wet and dry food, about $56 \%$ of cats were fed only dry food and less than $4 \%$ of cats received only wet food. Previous studies have shown that cats on a dry food diet were the most likely to suffer from urological syndrome [7].

\section{References}

1. R. Dorsch, C. Remer, C. Sauter-Louis, K. Hartmann, Tieraerztliche Praxis Ausgabe K: Kleintiere/Heimtiere, 42, 231-239 (2014)

2. A. V. Eggertsdottir, B. K. Saevik, I. Halvorsen, H. Sorum, Journal of Feline Medicine and Surgery, 13, 800-803 (2011)

3. S. D. Forrester, T. L. Towell, Veterinary Clinics of North America: Small Animal Practice, 45, 783-806 (2015)

4. J. M. Kruger, C. A. Osborne, J. P. Lulich, Veterinary Clinics of North America: Small Animal Practice, 39, 15-40 (2009)

5. S. Lew-Kojrys, E. Mikulska-Skupien, A. Snarska, et al., Veterinarni Medicina, 62, 386-393 (2017)

6. I. Martinez-Ruzafa, J. M. Kruger, R. Miller, et al., Journal of Feline Medicine and Surgery, 14, 729-740 (2012)

7. B. K. Saevik, C. Trangerud, N. Ottesen, et al., Journal of Feline Medicine and Surgery, 13, 410-417 (2011)

8. C. A. T. Buffington, J. L. Westropp, and D. J. Chew, J. Feline Med. Surg., 16, 385-394 (2014)

9. Companion Animal Parasite Council. CAPC General Guidelines, 17 (2013), http://www.capcvet.org/capc-recommendations/capc-general-guidelines

10. P. A. Defauw, I. Van de Maele, L. Duchateau, et al., J. Feline Med. Surg., 13, 967-975 (2011)

11. P. A. M. Defauw, I. Van de Maele, L. Duchateau, et al., J. Feline Med. Surg., 13, 967975 (2011)

12. S. L. Ellis, I. Rodan, H. C. Carney, et al., J. Feline Med. Surg., 15, 219-230 (2013)

13. T. Gluhek, J. W. Bartges, A. Callens, et al., J. Vet. Intern. Med., 26, 801 (2012)

14. E. Grigg, L. Pick, and B. Nibblett, J. Feline Med. Surg., 15, 280-284 (2012)

15. P. M. Hanno, D. A. Burks, J. Q. Clemens, et al., J. Urol., 185, 2162-2170 (2011) 
16. J. P. Lulich, J. M. Kruger, J. MacLeay, et al., J. Am. Vet. Med. Assoc., 243, 11471153 (2013)

17. J. C. Neilson, Behavioral management of cats with idiopathic cys- titis (2014), Available at: www.hillsvet.com/HillsVetUS/v1/portal/en/us/ content/research/felinelower-urinary-tract-disease-flutd/conf- pro-behav-mgmt-cats-idiopathic.pdf. Accessed 15 Apr (2014)

18. B. K. Sævik, C. Trangerud, N. Ottesen, et al., J. Feline Med. Surg., 13, 410-417 (2011)

19. G. Segev, H. Livne, E. Ranen, and E. Lavey, J. Feline Med. Surg., 13, 101-108 (2011)

20. A. K. Srivastava, B. Syed, Indian Journal of Canine Practice, 4, 94-5 (2011)

21. J. Stella, C. C. Croney, C. A. Buffington, Appl. Anim. Behav. Sci., 143, 157-163 (2013)

22. J. L. Stella, L. K. Lord, C. A. T. Buffington, J. Am. Vet. Med. Assoc., 238, 67-73 (2011)

23. H. M. Syme, Arab. J. Urology 10, 230-9 (2012)

24. A. Zohaib, Z. Taj, A. U. R. Sial, M. A. Naeem, M. Saqlein, Pakistan Vet. J., 33, 131-2 (2013) 